\title{
The Role of Advanced Manufacturing Technologies in Production Process Performance: A Causal Model
}

\author{
José Roberto Díaz-Reza ${ }^{1}{ }^{(\mathbb{D}}$, José Roberto Mendoza-Fong ${ }^{1}{ }^{\mathbb{D}}$, Julio Blanco-Fernández ${ }^{2}{ }^{\mathbb{D}}$, \\ José Antonio Marmolejo-Saucedo ${ }^{3}$ and Jorge Luis García-Alcaraz $4, *$ (i) \\ 1 Department of Electric and Computer Engineering, Universidad Autónoma de Ciudad Juárez, Juárez 32310, \\ Mexico \\ 2 Department of Mechanical Engineering, Universidad de La Rioja, 26004 La Rioja, Spain \\ 3 Universidad Panamericana. Facultad de Ingeniería, Augusto Rodin 498, Ciudad de México 03920, Mexico \\ 4 Department of Industrial and Manufacturing Engineering, Autonomous University of Ciudad Juarez, \\ Ciudad Juárez 32310, Mexico \\ * Correspondence: jorge.garcia@uacj.mx; Tel.: +52-656-6884843 (ext. 5433)
}

Received: 31 July 2019; Accepted: 4 September 2019; Published: 7 September 2019

Featured Application: Findings in this research can be used in decision-making process during the selection and implementation of advanced manufacturing technology in a manufacturing company.

\begin{abstract}
Advanced manufacturing technologies (AMT) require considerable investments that managers often avoid, which makes it difficult to link their production operations with the benefits reported in literature review. The present paper shows a structural equation model that integrates four latent variables to measure the relationship between the levels of advanced manufacturing technologies implementation (Stand-Alone Intermediate and Integrated Systems), as well as the benefits obtained in the productive systems. The variables are related to each other using six hypotheses in order to realise how the AMT implementation level affects the benefits obtained from a quantitative and statistical point of view. The model is evaluated through the partial least square technique with data from 383 responses to a survey. Findings show that Stand-Alone Systems contribute more to obtaining Production Benefits, followed by Integrated Systems and Intermediate Systems. Finally, a sensitivity analysis based on conditional probabilities was performed to evaluate scenarios at different implementation levels in AMT to know how they facilitate the acquisition of the benefits offered.
\end{abstract}

Keywords: advanced manufacturing technologies (AMT); production performance; manufacturing industry; SEM; sensitivity analysis

\section{Introduction}

As a matter of fact, manufacturing is evolving constantly as needs and technologies arise, allowing the customer to enjoy a variety of products at lower prices [1]. Therefore, in order to react to customer demand, companies can decide to invest in advanced manufacturing technologies (AMT) [2]. AMT is understood as the implementation of modern technologies to deliver existing and new products to the market, which are focused on design improvement, manufacturing, and information integration processes in technology systems throughout the supply chain to improve delivery, costs, quality, and flexibility that may be transferred into a competitive advantage [3]. Percival and Cozzarin [4] define AMT as a set of computer-based technologies that include: Computer-assisted design, robotics, technology groups, flexible manufacturing systems, automated material handling systems, storage and 
retrieval systems, numerically controlled computer machine tools, and bar codes or other automated identification techniques, integrated manufacturing by computer, just-in-time system, among others.

Small and Chen [5] classify AMT into three categories depending on the interaction level they have with other technologies, for instance, there may be Stand-Alone Systems, Intermediate Systems, and Integrated Systems, where, logically, each of these categories offer different benefits and implementation difficulties. Table 1 illustrates the classification for AMT proposed by Small and Chen [5] and supported by others researchers, as well as some operational benefits that can be gained after a successful implementation.

Table 1. AMT taxonomy.

\begin{tabular}{|c|c|}
\hline Category & Items \\
\hline Stand-Alone Systems $[4,6-9]$ & $\begin{array}{c}\text { Engineering and design technologies } \\
\text { Computer aided design (CAD) } \\
\text { Computer-aided planning process (CAPP) } \\
\text { Fabricating/Machining and Assembly Technologies } \\
\text { NC/CNC or DNC machines } \\
\text { Materials that work with laser (MWL) } \\
\text { Robots for lifting objects } \\
\text { Other type of robots }\end{array}$ \\
\hline Intermediate Systems $[4,6,9]$ & $\begin{array}{c}\text { Automated Material Handling Technologies } \\
\text { Automatic storage systems (AS/RS) } \\
\text { Automatic material handling systems (AMHS) } \\
\text { Automated Inspection and Testing Systems } \\
\text { Automated inspection test equipment (AITE) }\end{array}$ \\
\hline Integrated Systems $[4,6-9]$ & $\begin{array}{c}\text { Flexible Manufacturing Technologies } \\
\text { Flexible manufacturing (Cells or Systems) (FMC/FMS) } \\
\text { Computer-integrated manufacturing systems } \\
\text { Computer integrated manufacturing by (CIM) } \\
\text { Logistic Related Systems } \\
\text { Just in Time (JIT) } \\
\text { Materials requirement planification (MRP) } \\
\text { Manufacturing resources planification (MRP II) }\end{array}$ \\
\hline Production Benefits $[8,10]$ & $\begin{array}{l}\text { Reduction in the production cost } \\
\text { Reduction in the processing time } \\
\text { Increasement in product quality } \\
\text { Increasement in plant capacity } \\
\text { Improvement of the plant distribution } \\
\text { Better production organization } \\
\text { Reduction of set-up time } \\
\text { Increasement in reliability } \\
\text { Better usage of the available space }\end{array}$ \\
\hline
\end{tabular}

According to Meredith and Suresh [11], Stand-Alone Systems are robots and numerically controlled (NC) machine tools, although they can also be integrated into other systems and equipment. When the AMTs are linked to linked systems as automatic storage/recovery systems (AS/RS) and automated guided vehicle systems (AGVS) for move or facilitate material flow, they are called Intermediate Systems. However, if the Stand-Alone Systems come together or are integrated in manufacturing cells, such as in group technology lines (GT) or flexible manufacturing systems (FMS), then they are called Integrated Systems and can be linked with manufacturing resource planning (MRP II). When design, planning, material handling, manufacturing and support systems (for example, order entry, cost accounting, purchasing) are linked to each other through computer control, the factory is considered fully integrated, often known as CIM [12]. However, that taxonomy was proposed long time ago, and over time, new technologies have been applied to production systems which added in some 
categories, such as Factory Telemetry Technology [13], and software for data analysis in real time [14], among others.

Implementing AMT in the current globalized environment is one of the biggest challenges that companies are facing, since changes are required to be reflected in the organizational structure and work [15], which means an alteration in the status quo, a threat to people's interests in their jobs, and in the established way of doing certain tasks. Ordoobadi [16] makes two observations when analyzing the stages of the AMT adoption process, where the previous barriers have been reported, as well as the manufacturers' inability to recognize the potential benefits that are offered.

However, positive results from the proper AMT implementation have also been reported, such as quality, low cost, shorter delivery time, greater flexibility, better competitive advantage, and increased productivity [17]. For example, Garcia-Alcaraz, et al. [18] report a list of benefits obtained from the AMT implementation in manufacturing industries, which are classified as operational, productivity, administrative, and human resources. Therefore, these benefits are obtained only if the "appropiate" technologies are chosen, since otherwise, "inappropriate" technologies may reduce the competitiveness of companies and lead to a financial failure, because investments in AMT always require large economic amounts [19].

Thus, a relevant question regarding the AMT implementation process is to quantify the impact or benefits that can be obtained in the industry. Currently, there are a few articles that relate the characteristics and level of implementation of AMT along with the benefits obtained, where there are two weaknesses: The first is that the research is only focused on a specific AMT-for example, Choe [20] related AMT with organizational performance, Gothwal and Raj [21] analyzed only flexible manufacturing systems, García-Alcaraz, et al. [22] focused only on the just-in-time technique, Braglia and Gabbrielli [23] only considered robots, and Lee and Shin [12] analyzed only CIM practice. The second weakness is that AMT is associated with economic approaches to evaluate the investment [20,24,25] — for example, Chan, et al. [26] mentioned that the economic approach represents the traditional practice for evaluation, justification and selection for companies that expect such benefits. However, investment decisions in AMT should not be based solely on economic aspects, since there are also benefits associated with human, administrative, and production benefits, which managers should then integrate into the investment decision process.

In fact, due to the North American Free Trade Agreement (TLCAN), several foreign manufacturing companies, traditionally known as maquiladoras, arrived in Mexico. Currently, there are 5518 maquiladora industries in Mexico and they have implemented a lot of AMT [27]. A maquiladora is a factory located near the United States-Mexico border that operates with a favorable duty- or tariff-free basis [28]. They are a product of the Twin Plant Agreement and have certain tax advantages that make them attractive to businesses, mainly because of a low labor cost and high training in human resources.

Specifically, in the Mexican Chihuahua state, there are 510 maquiladoras and this represent $9.25 \%$ of the gross domestic product; however, from the 510 maquiladoras, 332 are established in Ciudad Juarez which is the main industrial sector in the city, employing 268,761 direct workers. Due to the amount of maquiladoras as well as the AMT implemented, the manufacturing industry is the most important industrial and economic sector of the city, where research regarding AMT implementation and benefits gained is required to facilitate decision making for managers regarding their investment, giving a quantitative relationship measurement between the investment and the benefits.

In order to provide knowledge about how the AMT implementation levels are related to the Production Benefits obtained by maquiladoras, this article seeks to quantify through a structural equation model (SEM) the effect that the level of implementation from the Stand-Alone Systems (CAD, CAM, CNC), Intermediate Systems (AS/RS, AMHS, AITE), and Integrated Systems (FMC/FMS, CIM, JIT, MRP and MRP II) have on the Production Benefits. The AMT categories and benefits gained are latent variables in the SEM and are related with six hypotheses that are tested statistically.

Likewise, a sensitivity analysis is presented to show how low and high implementation levels in the AMT categories are generating low and high Production Benefits, which is carried out based on 
the conditional probability. This sensibility analysis facilitates the decision making for managers and identifies the main risks when there are low implementation levels, and this type of analysis is one of the first to be reported.

This article is divided into five sections. Section 1 comprises the previous brief explanation. In Section 2, a literature review is presented and the SEM hypotheses are proposed regarding AMT implementation, as well as their relationship with the production benefits. In Section 3, the methodology that was used to statistically validate the model and hypothesis is detailed. Section 4 discusses the results obtained, the values of the effects from the model, its variance, and the sensitivity analysis. Finally, in Section 5, the conclusions and industrial implications from the results obtained are addressed.

\section{Literature Review and Hypotheses}

In this section, the different type of studies related to AMT are included; for example, Boer [29] investigated the interactions between the AMT implementation and integration, the acquisition of new management and organization principles. On the other hand, Bülbül, et al. [30] carried out an analysis on the relationship among the AMT investment, ownership structure, company size, and its performance in the motor vehicle industry in Turkey, and they concluded that investing in AMT provides a higher manufacturing performance, generates a better position in the market, a greater reputation, and customer attraction. In addition, Cardoso, et al. [31] proposed certain recommendations for AMT implementation, since companies require a structured and integrative approach. Also, Boyer, et al. [32] analyzed whether investments in AMT have better results on performance or not, comparing it with investments on infrastructure improvement; the results show that with investment in both, the industrial potential will be better deployed.

Similarly, there are some authors who have presented structural equation models that measure the impact of AMT on other variables; for example, Ghobakhloo and Azar [33] used an equation model where the impact of AMT on Lean Manufacturing tools (LM) was measured, such as "just in time", quality management, and agile manufacturing (AM) in order to measure operational, marketing, and financial performance. The results show that AMT is a key infrastructure that is necessary for LM and AM development.

Moreover, Kumar, et al. [34] presented a SEM from the automotive industry in India, where AMT implementation was linked with five success factors, namely, education and employee training, organizational structure, management know-how, technical know-how, and manufacturing strategy, which are related with redesign factors production systems, human resources, and organizational strategies. Their findings show that the manufacturing organizations should include activities to improve the workers skills. Finally, Altuntas, et al. [35] presented a SEM where the AMT effected the innovation, exportation, and performance of manufacturing companies in Turkey, where they found that there was strong and positive associations between the AMT implementation and the innovation, exportation, and company performance. Consequently, there have been many reported studies in which SEM is used to model AMT aspects.

However, there is a wide discussion about AMT investment strategy-while some authors recommend investing gradually and slowly in it, others suggest that the whole investment has to be made at once or only once [36], which may represent a high financial risk for the company. Thus, the tendency is that small companies only invest in Stand-Alone Systems that are cheaper and have low financial risk, and then, depending on the achieved success, Intermediate Systems are subsequently implemented [37]. Then, the Stand-Alone Systems, after their success, require Intermediate Systems, associated with the automated inspection (AITE) of the products that come out from the CNC or DNC machines, or robots that work in isolation, and are then integrated in material handling systems [38]. Therefore, the following hypothesis can be proposed:

Hypothesis 1 (H1). The Stand-Alone Systems level of implementation in AMT has a direct and positive effect on the Intermediate Systems level of implementation. 
Furthermore, Integrated Systems such as CIM, JIT, and the MRP family require the support of other technologies in order to be successful when implemented. For example, the automatic storage systems (AS/RS) are an essential support in the JIT implementation [39] and, in the same way, it is almost impossible to imagine a MRP system that does not integrate the capabilities of the systems into its plans and programs in automatic material handling systems (AMHS), automated inspection test equipment (AITE) [40] and currently, with Resource Description Framework (RDF) for better communication among technologies [41]. In other words, the Integrated Systems are reinforced with the Intermediate Systems in a productive system, therefore the following hypothesis is proposed:

Hypothesis 2 (H2). The Intermediate Systems level of implementation in a productive system has a direct and positive effect on the Integrated Systems level of implementation.

Moreover, the increase in product variability and the JIT inventory control systems implementation require a greater capacity to handle production activities at the production systems [42]. The products and lots of work that change more frequently produce immediate supplies, tools, material demands, adjustments and repairs of failures and breakdowns, where skills and experience are required to handle the CNC machines [42].

Ang, Sum and Chung [40] declared that MRP implementation systems require a series of factors, where one of them is the presence of NC, CAD, and CAPP systems in the production process, since this indicates that the company has invested in isolated technologies. Dhamija, et al. [43] presented a model to measure the integration level that CAD-CAPP-MRP-NC have in a productive system that may be transferred to more Integrated Systems. Also, Campos and Miguez [44] indicated that $\mathrm{CAD} / \mathrm{CAM} / \mathrm{CNC}$ systems are no longer efficient if they are not capable of being a system that favors or facilitates the integration of other technologies in the productive system. Therefore, the following hypothesis is proposed:

Hypothesis 3 (H3). The Stand-Alone Systems level of implementation in a production system has a direct and positive effect on the Integrated Systems level of implementation.

As a matter of fact, AMT has a crucial role in manufacturing systems, since it speeds up the production process and offer new opportunities for decision makers in their search for new applications on innovative developments [35]; in other words, it must be associated with the benefits that are obtained from its application, otherwise investment in this type of technology would not be justified. For instance, CAD software has an integrated functionality that allows the estimation, storage, and manipulation of vital information from a product-such as material characteristics, material lists, and costs-that is why, it is easily integrated into MRP systems [45] which facilitates the effective data management, reduces manufacturing errors, allows efficient and reliable communication through the supply chain, and gives an opportunity to improve the usage of products, processes, and information management that was not available before.

In the same way, CAD and CAPP help the materials flow within the company and the monitoring of several activities during the design and production process. For example, Zhou, et al. [46] mentioned that the integration of these systems guarantees agility and flexibility in the supply chain; also, recent studies have shown that when CAPP is integrated into systems, such as the internet, a better traceability of productive processes can be obtained [47].

Likewise, Brecher, et al. [48] stated that, nowadays, CAM is able to offer quality products because it is easy to operate and it is a type of technology that is available for most companies. A similar hypothesis was made by Brecher and Lohse [49], who pointed out that computerized systems allow better control of activities. In addition, robots have been performing the heaviest and most dangerous tasks in production systems for a long time, which has also been reflected in productivity indexes [50]. Finally, Zhang, et al. [51] claimed that systems based on CNC, CAM, and AMHS make production more flexible and agile. 
For this reason, considering that companies invest in Stand-Alone Systems to obtain a series of benefits, the following hypothesis is proposed:

Hypothesis 4 (H4). The Stand-Alone Systems level of implementation has a direct and positive effect on the Production Benefits obtained.

Moreover, the Intermediate Systems refer to materials transportation and storage of automatic systems, as well as to inspection systems and their implementation in production systems that have been widely reported. For example, Lin, et al. [52] mention that AMHS systems help companies in India to reduce the number of accidents due to material handling, increase their industrial safety indexes, and avoid loss of raw material due to inappropriate usage. For instance, Glüer and Sturm [53] report a simulation implementation to determine the benefits that can be achieved with the usage of AMSH.

In the same way, automated inspection systems have evolved and their application in production systems is widely reported. For example, Lemos, et al. [54] indicated that intelligent manufacturing cannot be conceived without the support of computer vision systems while Baena, et al. [55] suggested that vision systems are a fundamental pillar in the Industry 4.0, which support decision systems. According to the previous information, it is observed that an appropriate implemented Intermediate System may offer benefits in the productive system, and the following hypothesis is presented:

Hypothesis 5 (H5). The Intermediate Systems level of implementation has a direct and positive effect on the Production Benefits obtained.

Although Integrated Systems are the most expensive and difficult to implement, they are still attractive for managers due to the benefits they offer. For example, Fullerton and McWatters [56] claimed that JIT offers a series of benefits that are directly reflected in the productive system; Maiga and Jacobs [57] performed an analysis of the effects that JIT has when it is implemented, where it indicated that the deliveries on time and fulfillment of complete orders were always obtained. García-Alcaraz, et al. [58] reported a factorial analysis on the different benefits obtained from JIT in the productive systems, and Singh and Garg [59] showed a list of 33 benefits identified in a literature review.

In the same way, the benefits from MRP systems have been reported by Schroeder, et al. [60] who had already reported studies justifying the investment in MRP. In addition, Sum, et al. [61] pointed out the operative benefits from the tool by having better control and traceability of the requirements; and finally, Wang, et al. [62] indicated that JIT and MRP are techniques that must be properly integrated to ensure a better supply chain performance in production systems. Therefore, in the present research, the following hypothesis is proposed:

Hypothesis 6 (H6). The Integrated Systems level of implementation has a direct and positive effect on Production Benefits in companies.

Figure 1 portrays graphically the hypotheses that have been previously proposed. 


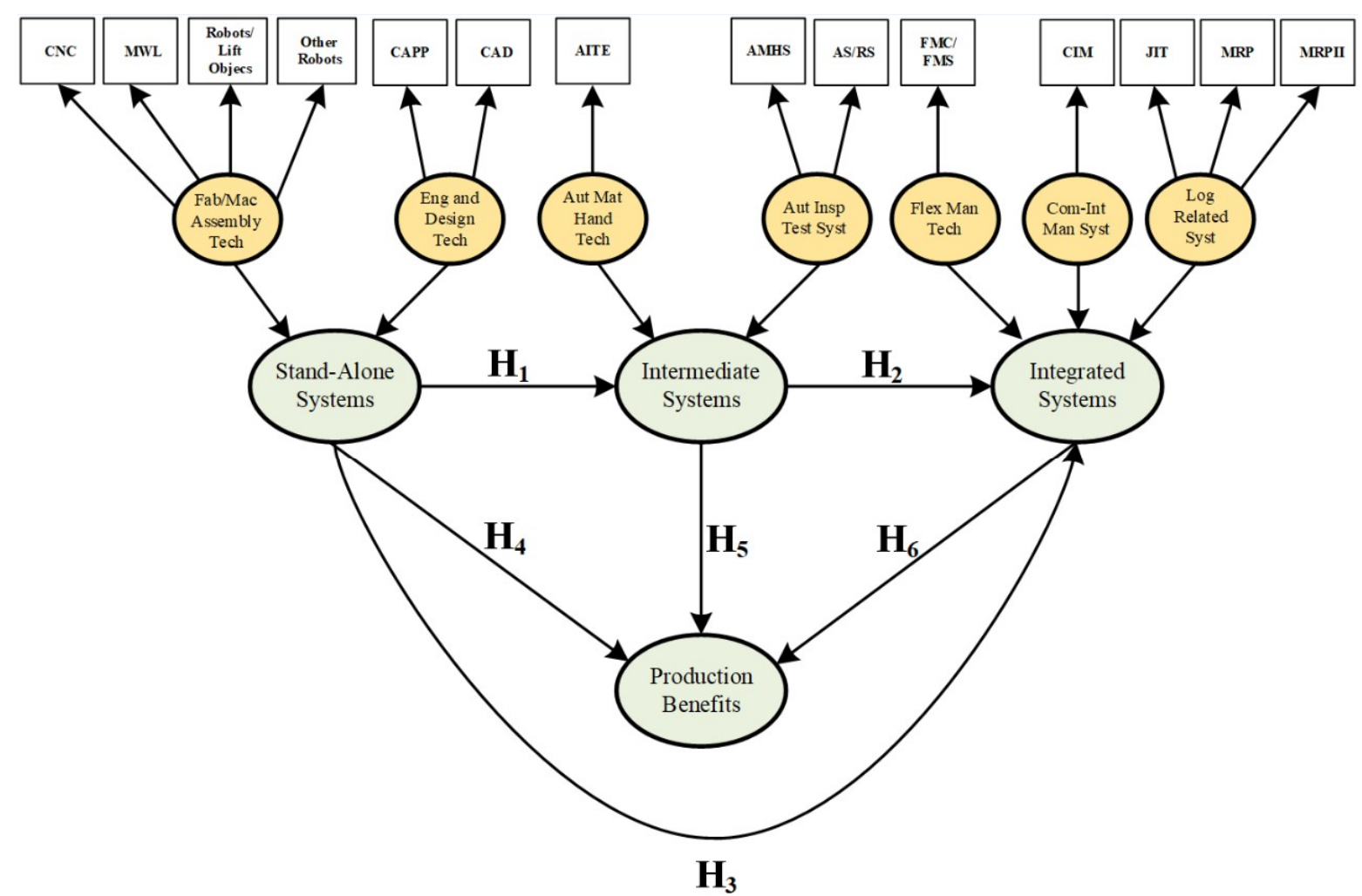

Figure 1. Proposed Model.

\section{Materials and Methods}

In this section, the procedure that was followed to write this article is described, which consists of six steps.

\subsection{Questionnaire Development}

In order to quantify the relationship between the AMT implementation level and the benefits gained, it was necessary to validate the hypotheses statistically in the model, therefore some data was required from companies. A questionnaire was designed to get the data from companies, which had four sections: The first section was aimed to get demographic information from respondents, such as gender, job position, industrial sector, years of experience, among others; a second section was aimed to get the implementation level for AMT in the company-the classification given by Small and Chen [6] was used-where the classification was composed by 14 technologies (items) divided into three categories, which are illustrated in Table 1. A third section was aimed to identify the benefits obtained from the AMT implementation where a total of 36 items were identified and divided into six categories (design, production, human resources, commercial, material benefits, and processes); however, in the current research, only the Production Benefits were analyzed (9 items). A fourth section was aimed at identifying the main problems faced in the implementation process of AMT, and 26 problems were divided into three categories (selection processes, implementation process, and operation), which are not analyzed in this article.

A five point Likert scale was used to answer the questionnaire, where 1 meant that the AMT has not been implemented or the benefit has not been obtained, while 5 meant that there was an excellent AMT implementation or that the benefit is always obtained [63]. 


\subsection{Questionnaire Application}

The questionnaire was applied to the maquiladora industries in Mexico because those companies are characterized by a high technological level and AMT implementation [64], and where research about the benefits gained are required. The survey was focused on the personnel involved in production processes who are directly familiar with AMT usage and management (managers, engineers, supervisors, technicians, and operators), therefore, the sampling is stratified, and then the participants proposed other colleagues who should answer the questionnaire, so as a consequence, the snowball method was implemented.

An email was sent to potential respondents to arrange an appointment to answer the questionnaire in a personalized way. If the appointment was canceled, then a new one was scheduled; however, if after three attempts the interview could not be performed, that case was excluded. The following inclusion principles are applied: Participants must have had at least two years working in the same job position, and respondents must have had participated in the selection and implementation process for any kind of AMT in order for them to know the results obtained from it.

\subsection{Database Registation and Debugging}

A database was created in the SPSS $24{ }^{\circledR}$ software, where all the latent variables and each of the items were registered. In addition, the database is purified by the following activities:

1. The standard deviation for each of the questionnaires was estimated; therefore, if it was under 0.50 , that questionnaire was not considered, because there was minimal commitment from the respondent.

2. The lost values for each of the questionnaires were identified; those that have more than $10 \%$ of lost values were not considered, otherwise, they were replaced by the median.

3. Extreme values were identified and replaced by the median.

\subsection{Questionnaire Validation}

Data validation was performed to database before any type of analysis, where a series of indexes were obtained. Table 2 shows the indexes or parameters used to measure the validity of the latent variables in the model [65].

Table 2. Questionnaire validation indexes.

\begin{tabular}{ccc}
\hline Indexes & Measurement & Suggested Value \\
\hline $\mathrm{R}^{2}$ & Predictive parametric validation & $\geq 0.20$ \\
Adjusted $\mathrm{R}^{2}$ & Internal consistency & $\geq 0.20$ \\
Composite Reliability & Internal consistency & $\geq 0.70$ \\
Cronbach's Alpha & Discriminant validity & $\geq 0.70$ \\
Average Variance Extracted & Collinearity & $\geq 0.50$ \\
Full Collin. VIF & Predictive non-parametric validity & $>0.30$ \\
$\mathrm{Q}^{2}$ &
\end{tabular}

\subsection{Structural Equation Model}

If latent variables qualified for the validation process, they were integrated into the model. In order to evaluate the model in Figure 1, structural equation model (SEM) technique was selected, which was used to explore and test the relationship between variables [66] that include regression analysis, factor analysis, multiple correlations, and route analysis of route. In addition, SEM was chosen since it allowed the analysis of second-order variables, which are latent variables where indicators are other latent variables, in other words, SEM allows the measurement of not only the direct effect, but also the indirect and total effects [67], such as the proposed model in Figure 1. 
According to Hair, et al. [68], the partial least squares can be estimated according to Equations (1) and (2) from a matrix point of view:

$$
\begin{aligned}
& X=T P^{T}+E \\
& Y=U Q^{T}+F
\end{aligned}
$$

where

$X$ is an $n x m$ matrix of predictors or independent variables,

$Y$ is a matrix of responses or dependent variables,

$T$ and $U$ are matrices that are, respectively, projections of $X$ (the $X$ score, component or factor matrix), and projections of $Y$ (the $Y$ scores),

$P$ and $Q$ are, respectively, $m x l$ and $p x l$ orthogonal loading matrices,

$E$ and $F$ matrices are the error after calculus.

The main idea in PLS is to generate a regression equation for the dependent latent variable $Y$ as a function of the standardized variable $X$, generating an equation as follows:

$$
Y=\beta X
$$

Observe that in Equation (3), the term $\beta_{0}$ is absent and that is because the PLS technique uses standardized values. However, it is possible that a dependent variable is explained by $n$ independent variables and then Equation (3) is converted into Equation (4).

$$
Y=\beta_{1} X_{1}+\beta_{2} X_{2}+\cdots \beta_{n} X_{n}
$$

In this paper, the model was evaluated by the software WarpPLS $6{ }^{\circledR}$ (ScriptWarp Systems, Laredo, TX, USA) that is based on partial least squares (PLS), which is recommended in cases where there is no normality or the values are expressed in ordinal scales [69], which has been used in multiple works, for instance, in Moqbel, et al. [70] where an SEM was presented to examine the use of social networking sites by members of an organization, as well as its effect on job satisfaction, organizational commitment, and job performance. Before interpreting the model, the following efficiency indexes were analyzed:

1. Average path coefficient (APC) acceptable if $p<0.05$

2. Average R-squared (ARS) acceptable if $p<0.05$

3. Average adjusted R-squared (AARS) acceptable if $p<0.05$

4. Average block VIF (AVIF) acceptable if $\leq 5$, ideally $\leq 3.3$

5. Average full collinearity VIF (AFVIF) acceptable if $\leq 5$, ideally $\leq 3.3$

6. Tenenhaus Goodness of Fit $(\mathrm{GoF})$ small $\geq 0.1$, medium $\geq 0.25$, large $\geq 0.36$

\subsection{Direct Effects, Indirect Effects, Total Effects, and Size Effects}

As a matter of fact, within the SEM, three effects are measured between the latent variables in the model; first, the direct effects, which are represented by arrow segments and can be seen in Figure 1 , which represent each of the hypotheses to be tested. Also, for each direct effect, a value of $\beta$ is reported, which is another term that is often used to refer to the path coefficients in SEM analyses based on PLS, which it is also commonly used in multiple regression analysis [71]. In addition, there is a $p$-value associated to every $\beta$ value, which represents the level of significance for the statistical hypothesis test with a confidence level of $95 \%$ where the null and alternative hypotheses are:

$$
\begin{aligned}
& \mathrm{H}_{0}: \beta=0 \\
& \mathrm{H}_{1}: \beta \neq 0
\end{aligned}
$$

The second effects are the indirect effects and occur between two or more variables through mediating variables, in other words, an independent variable may have some effect on a dependent 
variable through a third or more dependent variables. In addition, the total effects are the sum of the direct and indirect effects. Finally, the size effects (SE) are reported, which is a measure of the variance explained by an independent variable in a dependent variable. Kock [71] mentioned that the suggested values are $0.02,0.15$, and 0.35 , respectively, for size effects, where values under 0.02 represent effects that are too weak to be considered relevant from a practical point of view, even when the corresponding $p$-values are statistically significant; a situation that may occur with large sample sizes [69].

\subsection{Sensitivity Analysis}

Specifically, PLS analyzes standardized data, therefore, it is possible to obtain probabilities that are significant for managers and decision-makers, since they allow the knowledge of different occurrence and risks scenarios [71]. In this article, two kind of scenarios were analyzed, the $P(Z>1)$ for high scenarios and $\mathrm{P}(Z<-1)$ for low scenarios for every latent variable, where $Z$ is a standardized value for the latent variable. The scenarios analyzed are as follow:

- The probability of finding independently the latent variables at their high $(Z>1)$ and low $(Z<-1)$ levels without any interaction among them.

- The probability of finding the two variables (independent and dependent) of a hypothesis in the following stages, either jointly (represented by " $\&$ ") or conditionally (represented by "If"). The combinations are:

1. For joint (\&) $\mathrm{P}\left(\mathrm{Z}_{\mathrm{i}}>1\right)$ and $\mathrm{P}\left(\mathrm{Z}_{\mathrm{d}}>1\right)$, and for conditional probability (if) $\mathrm{P}\left(\mathrm{Z}_{\mathrm{i}}>1\right) \mid \mathrm{P}\left(\mathrm{Z}_{\mathrm{d}}>1\right)$

2. For joint (\&) $\mathrm{P}\left(\mathrm{Z}_{\mathrm{i}}>1\right)$ and $\mathrm{P}\left(\mathrm{Z}_{\mathrm{d}}<-1\right)$, and for conditional probability (if) $\mathrm{P}\left(\mathrm{Z}_{\mathrm{i}}>1\right) \mid \mathrm{P}$ $\left(\mathrm{Z}_{\mathrm{d}}<-1\right)$

3. For joint (\&) $\mathrm{P}\left(\mathrm{Z}_{\mathrm{i}}<-1\right)$ and $\mathrm{P}\left(\mathrm{Z}_{\mathrm{d}}>1\right)$, and for conditional probability (if) $\mathrm{P}\left(\mathrm{Z}_{\mathrm{i}}<-1\right) \mid \mathrm{P}$ $\left(Z_{d}>1\right)$

4. For joint (\&) $\mathrm{P}\left(\mathrm{Z}_{\mathrm{i}}<-1\right)$ and $\mathrm{P}\left(\mathrm{Z}_{\mathrm{d}}<-1\right)$, and for conditional probability (if) $\mathrm{P}\left(\mathrm{Z}_{\mathrm{i}}<-1\right) \mid \mathrm{P}$ $\left(Z_{\mathrm{d}}<-1\right)$

where $Z_{i}$ is an independent latent variable and $Z_{d}$ is a dependent latent variable. Low and high implementation levels for a standardized latent variable is illustrated in Figure 2 as follows:
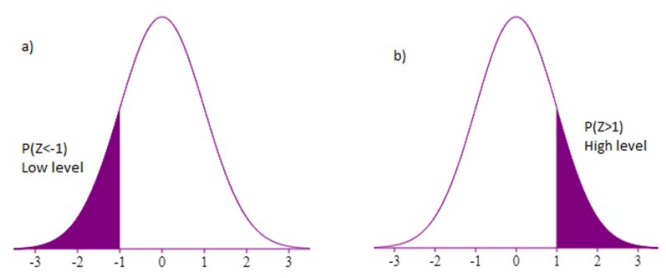

Figure 2. Low (a) and high (b) levels in AMT implementation.

According to Ross [72], conditional probability is fundamental because it enables decision makers to estimate risks according to different scenarios. In this research, for example, it is important to determine the possible occurrence in the dependent latent variable, since the independent variable has happened, where the formula can be the following Equation (7):

$$
P\left(Z_{d} \mid Z_{i}\right)=\frac{P\left(Z_{i} \cap Z_{d}\right)}{P\left(Z_{i}\right)}
$$

\section{Results}

In the following section, the results from the model analysis are described. 


\subsection{Analysis of the Sample}

After debugging the database, 383 items were obtained that were valid. In addition, Table 3 illustrates the data from the surveyed industrial sectors, where the Automotive sector predominates with a participation of $48.8 \%$, followed by the machinery sector with $25 \%$, and electronic sector with $11.5 \%$. We observe that 10 people that were interviewed did not answer this type of question.

Table 3. Industrial sector.

\begin{tabular}{ccc}
\hline Industrial Sector & Frequency & Percent \\
\hline Automotive & 187 & 48.8 \\
Machinery & 96 & 25 \\
Electronics & 44 & 11.5 \\
Electric & 32 & 8.4 \\
Not Answer & 10 & 2.6 \\
Logistics & 9 & 2.3 \\
Aeronautics & 5 & 1.3 \\
Total & 383 & 100 \\
\hline
\end{tabular}

In addition, Table 4 summarizes the job positions from the people interviewed, and it can be highlighted that those who participated the most were the production floor supervisors (83.02\%), who are those who have direct knowledge about the machines under their charge, followed by $5.5 \%$ that corresponded to technicians, who are those who check that machines are working correctly. Finally, the Table 4 job positions is completed by managers, engineers, among others, where 19 people did not answer this related question.

Table 4. Job position.

\begin{tabular}{ccc}
\hline Job & Frequency & Percent \\
\hline Supervisor & 318 & 83.02 \\
Technician & 21 & 5.5 \\
Not answer & 19 & 5 \\
Manager & 14 & 3.7 \\
Other & 9 & 2.3 \\
Engineer & 2 & 0.5 \\
Total & 383 & 100 \\
\hline
\end{tabular}

\subsection{Questionnaire Validation}

Table 5 presents the indexes implemented in the validation of each of the variables used in the SEM, where it is observed that all are achieved according to the expected values.

Table 5. Latent variable validation.

\begin{tabular}{ccccc}
\hline Index & $\begin{array}{c}\text { Stand-Alone } \\
\text { Systems }\end{array}$ & $\begin{array}{c}\text { Integrated } \\
\text { Systems }\end{array}$ & $\begin{array}{c}\text { Intermediate } \\
\text { Systems }\end{array}$ & $\begin{array}{c}\text { Production } \\
\text { Benefits }\end{array}$ \\
\hline $\mathrm{R}^{2}$ & & 0.566 & 0.405 & 0.428 \\
Adjusted R & & 0.564 & 0.404 & 0.424 \\
Composite Reliability & 0.871 & 0.880 & 0.867 & 0.950 \\
Cronbach's Alpha & 0.705 & 0.796 & 0.693 & 0.941 \\
Avg. Var. Extrac. & 0.772 & 0.710 & 0.765 & 0.679 \\
Full Collin. VIF & 1.847 & 2.641 & 2.536 & 1.730 \\
$\mathrm{Q}^{2}$ & & 0.567 & 0.404 & 0.430 \\
\hline
\end{tabular}




\subsection{Structural Equation Model}

Table 6 portrays the values from the SEM adjustment indexes that are illustrated in Figure 3. According to the APC, ARS, and AARS values, as well as their associated $p$-values that are under 0.05 , it is concluded that the latent variables meet the required values.

Table 6. Evaluated model and quality indexes.

\begin{tabular}{cll}
\hline Index & Value & $p$-Value \\
\hline Average path coefficient (APC) & 0.364 & $p<0.001$ \\
Average R-squared (ARS) & 0.467 & $p<0.001$ \\
Average adjusted R-squared (AARS) & 0.464 & $p<0.001$ \\
Average block VIF (AVIF) acceptable if $\leq 5$, ideally $\leq 3.3$ & 1.946 & \\
Average full collinearity VIF (AFVIF) acceptable if $\leq 5$, ideally $\leq 3.3$ & 2.188 & \\
Tenenhaus GoF (GoF) small $\geq 0.1$, medium $\geq 0.25$, large $\geq 0.36$ & 0.584 & \\
\hline
\end{tabular}

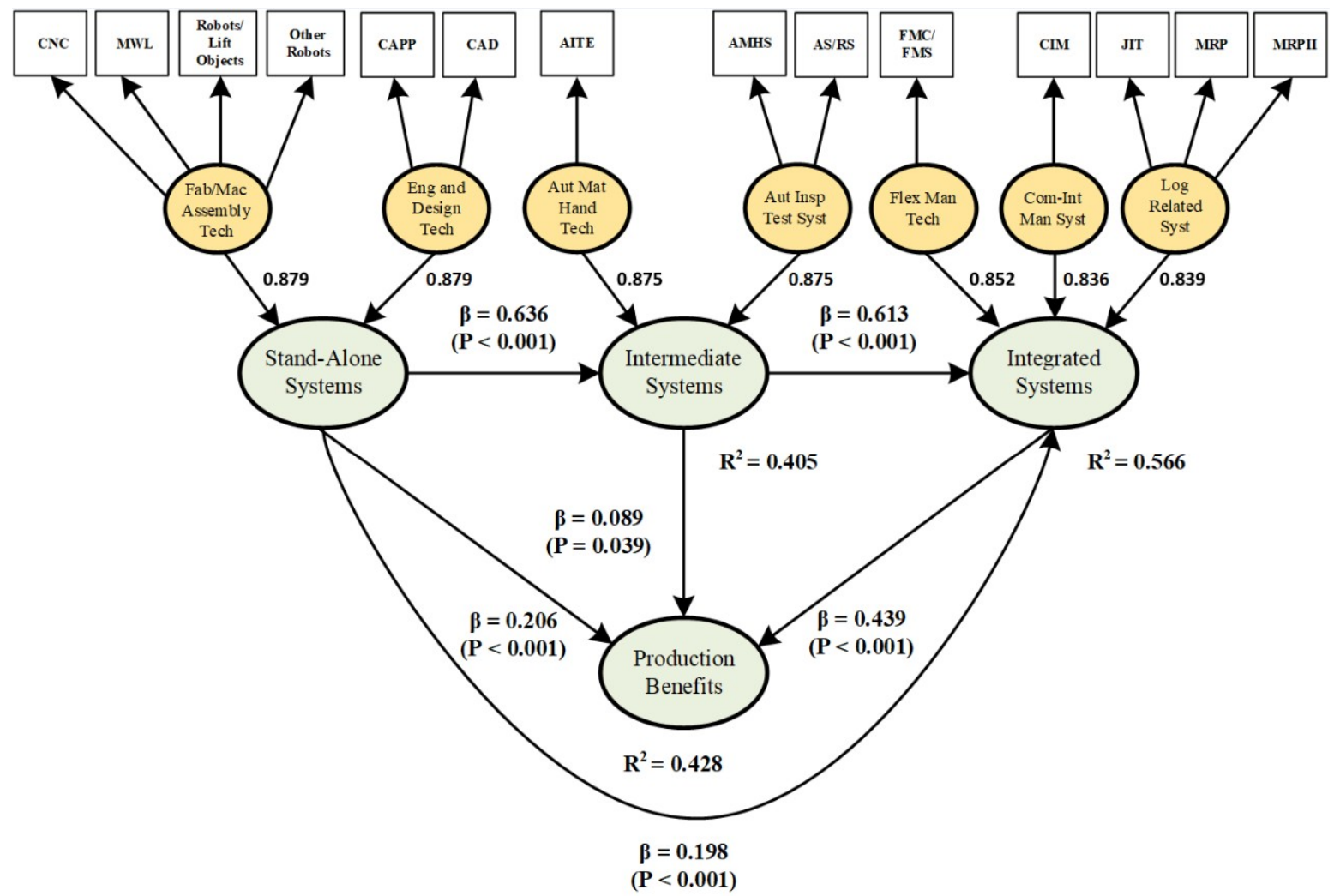

Figure 3. Evaluated Model.

\subsubsection{Direct Effects}

Figure 2 illustrates the direct effects that help to validate the hypotheses proposed in Figure 1. In addition, each hypothesis is associated with a $\beta$ and a $p$-value; according to these values, it was concluded that all values were statistically significant, since they were under 0.05 . Also, it can be observed that the largest effect is from Stand-Alone Systems towards Intermediate Systems with a value of $\beta=0.636$, which indicated that each time the first latent variable increases its standard deviation in one, the second variable increases in 0.636 units, which indicates that Stand-Alone Systems facilitate the Intermediate Systems implementation. A similar interpretation can be obtained from the following relationships between variables or hypotheses, where Table 7 illustrates a summary about the hypotheses conclusions. 
Table 7. Conclusions of the hypotheses.

\begin{tabular}{cccccc}
\hline $\mathbf{H}_{\mathbf{i}}$ & Independent Variable & Dependent Variable & $\mathbf{B}$ & $\boldsymbol{p}$-Value & Conclusion \\
\hline $\mathrm{H} 1$ & Stand-Alone Systems & Intermediate Systems & 0.636 & $<0.001$ & Accepted \\
$\mathrm{H} 2$ & Intermediate Systems & Integrated Systems & 0.613 & $<0.001$ & Accepted \\
$\mathrm{H} 3$ & Stand-Alone Systems & Integrated Systems & 0.198 & $<0.001$ & Accepted \\
$\mathrm{H} 4$ & Stand-Alone Systems & Production Benefits & 0.206 & $<0.001$ & Accepted \\
$\mathrm{H} 5$ & Intermediate Systems & Production Benefits & 0.089 & $=0.039$ & Accepted \\
$\mathrm{H} 5$ & Integrated Systems & Production Benefits & 0.439 & $<0.001$ & Accepted \\
\hline
\end{tabular}

Figure 3 describes the $\mathrm{R}^{2}$ value while Table 8 shows the contribution of each independent latent variable in that value. In this way, 0.428 from the Production Benefits variable is explained in 0.106 by the Stand-Alone Systems variable, 0.274 by Integrated Systems, and 0.048 by Intermediate Systems. In the same way, the 0.566 of $\mathrm{R}^{2}$ from the Integrated Systems variable is explained in 0.451 by the Intermediate Systems variable, and in 0.115 by the Stand-Alone Systems variable.

Table 8. $\mathrm{R}^{2}$ contribution.

\begin{tabular}{ccccc}
\hline \multirow{2}{*}{$\begin{array}{c}\text { Dependent } \\
\text { Variable }\end{array}$} & \multicolumn{3}{c}{ Independent Variable } & \multirow{2}{*}{ Total R $^{2}$} \\
\cline { 2 - 3 } & Stand-Alone Systems & Integrated Systems & Intermediate Systems & \\
\hline Integrated Systems & 0.115 & & 0.451 & 0.566 \\
Intermediate Systems & 0.405 & 0.274 & 0.048 & 0.405 \\
Production Benefits & 0.106 & 0.428 \\
\hline
\end{tabular}

\subsubsection{Indirect Effects}

In addition, Table 9 presents the total indirect effects, their $p$-value, and the SE. According to the $p$-value, it is concluded that all values are statistically significant. Also, the greatest effect is from the Stand-Alone Systems variable towards the Integrated Systems variable with a value of 0.390 and a $\mathrm{SE}=0.227$, which is greater than the direct effect, where it can be concluded that in order to have Integrated Systems from isolated systems, it is essential to go through the Intermediate Systems first. The previous information indicates that when Stand-Alone Systems increases its standard deviation in one-unit, Integrated Systems increases in 0.39 units; a similar interpretation is described for the other indirect effects.

Table 9. Total indirect effects.

\begin{tabular}{ccc}
\hline \multirow{2}{*}{ Dependent Variables } & \multicolumn{2}{c}{ Independent Variables } \\
\cline { 2 - 3 } & Stand-Alone Systems & Intermediate Systems \\
\hline Integrated Systems & $0.390 p<0.001 \mathrm{ES}=0.227$ \\
Production Benefits & $0.315 p<0.001 \mathrm{ES}=0.162$ & $0.269 p<0.001 \mathrm{ES}=0.144$ \\
\hline
\end{tabular}

\subsubsection{Total Effects}

Table 10 shows the total effects between variables, the $p$-value, and the associated SE. In addition, it is observed that all the effects are statistically significant since the $p$-values are under 0.05 . Also, the largest total effect is between the Stand-Alone Systems variable and the Intermediate System variable, with a value of 0.636 (direct effect) and a $\mathrm{SE}=0.342$, followed by the relationship between the Intermediate Systems variable with the Integrated Systems variable, with a value of 0.613 and a SE $=0.451$. 
Table 10. Total effects.

\begin{tabular}{cccc}
\hline \multirow{2}{*}{ Dependent Variable } & \multicolumn{3}{c}{ Independent Variable } \\
\cline { 2 - 4 } & Stand-Alone Systems & Intermediate Systems & Integrated Systems \\
\hline Integrated Systems & $0.588 p<0.001 \mathrm{ES}=0.342$ & $0.613 p<0.001 \mathrm{ES}=0.451$ & \\
Intermediate Systems & $0.636 p<0.001 \mathrm{ES}=0.405$ & & \\
Production Benefits & $0.521 p<0.001 \mathrm{ES}=0.269$ & $0.358 p<0.001 \mathrm{ES}=0.192$ & $0.439 p<0.001 \mathrm{ES}=0.274$ \\
\hline
\end{tabular}

\subsubsection{Sensitivity Analysis}

Table 11 presents the sensitivity analysis for each of the hypotheses proposed in Figure 1, based on the probability of the two high (+) and low (-) scenarios for each of the variables in the hypotheses. For example, the probability that the Stand-Alone Systems variable is presented independently at its high level is 0.193 , while at its low level is 0.146 .

Table 11. Sensitivity analysis.

\begin{tabular}{|c|c|c|c|c|c|c|c|c|c|}
\hline \multirow[b]{2}{*}{ Probability } & & \multicolumn{2}{|c|}{ Stand-Alone Systems } & \multicolumn{2}{|c|}{ Integrated Systems } & \multicolumn{2}{|c|}{ Intermediate Systems } & \multicolumn{2}{|c|}{ Production Benefits } \\
\hline & & $\begin{array}{c}+ \\
0.193\end{array}$ & $\begin{array}{c}- \\
0.146\end{array}$ & $\begin{array}{c}+ \\
0.149\end{array}$ & $\begin{array}{c}- \\
0.172\end{array}$ & $\begin{array}{c}+ \\
0.151\end{array}$ & $\begin{array}{c}- \\
0.149\end{array}$ & $\begin{array}{c}+ \\
0.159\end{array}$ & $\begin{array}{c}- \\
0.131\end{array}$ \\
\hline Stand-Alone & + & & & 0.097 & 0.005 & 0.089 & 0.005 & 0.065 & 0.005 \\
\hline Systems & - & & & 0.000 & 0.070 & 0.000 & 0.065 & 0.008 & 0.060 \\
\hline Integrated & + & & & & & 0.081 & 0.003 & 0.073 & 0.003 \\
\hline Systems & - & & & & & 0.003 & 0.104 & 0.030 & 0.068 \\
\hline Intermediate & + & & & & & & & 0.052 & 0.008 \\
\hline Systems & - & & & & & & & 0.005 & 0.050 \\
\hline
\end{tabular}

Similarly, the probability of the combination (ridge and column crossing) is shown, that is, that these two variables are presented in combined manner $(++,+-,-+$, and -$)$ for each hypothesis, for example, the probability that the Stand-Alone Systems variable is presented at its high level and Integrated Systems at its high level is 0.097, and if both are presented at their low level is 0.070, therefore, it is more likely to have high scenarios for these hypotheses. In addition, if the scenarios for the different hypotheses are observed, it is seen that there are low probabilities of occurrence, which suggests that to increase these values where the AMT implementation is mostly successful, it depends on the appropriate technology choices.

Furthermore, Table 12 portrays the sensitivity analysis for the conditional probability of each of the variables in the hypotheses, that is, the probability that a favorable or unfavorable scenario will arise in the dependent variable due to a favorable or unfavorable scenario in the independent variable. For instance, the probability that high results will be obtained in the Integrated Systems variable if high results have been obtained in the Stand-Alone Systems variable (Integrated Systems|Stand-Alone Systems), is 0.500 . On the other hand, the probability of having low levels in Intermediate Systems because there are low levels in the Stand-Alone Systems variable, is 0.446 , which indicates a possible risk. 
Table 12. Conditional probability (If).

\begin{tabular}{|c|c|c|c|c|c|c|}
\hline $\mathbf{H}_{\mathbf{i}}$ & Level & Dependent Variable & Condition & Independent Variable & Level & Probability \\
\hline \multirow{4}{*}{$\mathrm{H}_{1}$} & + & Intermediate Systems & If & Stand-Alone Systems & + & 0.459 \\
\hline & + & Intermediate Systems & If & Stand-Alone Systems & - & 0.000 \\
\hline & - & Intermediate Systems & If & Stand-Alone Systems & + & 0.027 \\
\hline & - & Intermediate Systems & If & Stand-Alone Systems & - & 0.446 \\
\hline \multirow{4}{*}{$\mathrm{H}_{2}$} & + & Integrated Systems & If & Intermediate Systems & + & 0.534 \\
\hline & + & Integrated Systems & If & Intermediate Systems & - & 0.018 \\
\hline & - & Integrated Systems & If & Intermediate Systems & + & 0.017 \\
\hline & - & Integrated Systems & If & Intermediate Systems & - & 0.702 \\
\hline \multirow{4}{*}{$\mathrm{H}_{3}$} & + & Integrated Systems & If & Stand-Alone Systems & + & 0.500 \\
\hline & + & Integrated Systems & If & Stand-Alone Systems & - & 0.000 \\
\hline & - & Integrated Systems & If & Stand-Alone Systems & + & 0.027 \\
\hline & - & Integrated Systems & If & Stand-Alone Systems & - & 0.482 \\
\hline \multirow{4}{*}{$\mathrm{H}_{4}$} & + & Production Benefits & If & Stand-alone Systems & + & 0.338 \\
\hline & + & Production Benefits & If & Stand-alone Systems & - & 0.054 \\
\hline & - & Production Benefits & If & Stand-alone Systems & + & 0.027 \\
\hline & - & Production Benefits & If & Stand-alone Systems & - & 0.411 \\
\hline \multirow{4}{*}{$\mathrm{H}_{5}$} & + & Production Benefits & If & Intermediate Systems & + & 0.345 \\
\hline & + & Production Benefits & If & Intermediate Systems & - & 0.035 \\
\hline & - & Production Benefits & If & Intermediate Systems & + & 0.052 \\
\hline & - & Production Benefits & If & Intermediate Systems & - & 0.333 \\
\hline \multirow{4}{*}{$\mathrm{H}_{6}$} & + & Production Benefits & If & Integrated Systems & + & 0.491 \\
\hline & + & Production Benefits & If & Integrated Systems & - & 0.030 \\
\hline & - & Production Benefits & If & Integrated Systems & + & 0.018 \\
\hline & - & Production Benefits & If & Integrated Systems & - & 0.394 \\
\hline
\end{tabular}

\section{Discussion, Conclusions and Industrial Implications}

\subsection{The Most Important Effects and Their Industrial Implications}

- $\quad$ The largest direct effect between the latent variables is from Stand-Alone Systems on Intermediate Systems with a value of 0.636 , which indicates that having an appropriate implementation of technologies, such as CAD, CAPP, CNC, and MWL will ease the implementation of automated material handling and inspection, as well as testing systems, consequently. This finding is essential for managers, because it indicates that Stand-Alone Systems support the Intermediate Systems implementation that have a higher automation and integration level, taking advantage of the experience obtained by operators, as is indicated by Alimohammadlou and Eslamloo [73].

- The second biggest direct effect is between Intermediate Systems and Integrated Systems with $\beta=0.613$, which indicates that technologies as AS/RS, AMHS, and AITE will support the FMC/FMS, CIM, JIT, MRP, and MRP II. This finding is common sense because they are related to material flow or production organization. For instance, it is reported that AS/RS and AMHS facilitate JIT, because they support the material flow $[62,74]$.

- In the same way, Stand-Alone Systems are those that have the greatest total effect on the Production Benefits (0.521); as a result, their appropriate implementation will improve productivity indexes such as low cost production and processing time. However, with Stand Alone Systems managers can also obtain better quality, plant capacity, and distribution. Also, this relationship has the greatest indirect effect with a value of 0.390 through Intermediate Systems, and it suggests that Stand-Alone Systems are the most relevant AMT in the maquiladora industry, because it is a result of the support of other more integrated technologies.

- $\quad$ Finally, the direct effect from Integrated Systems on Production Benefits have a value of 0.439 , which indicates an AMT integration flow, because taking care of the biggest direct effects, the following route seems to be crucial among variables, indicating that the AMT implementation process is gradual: 
In other words, managers must start the AMT implementation process with Stand-Alone Systems, and after acquire experience from those technologies, then Intermediate Systems can be performed, and once again they must be focused on obtain enough experience for finalizing the implementation process with Integrated Systems to guarantee Production Benefits.

\subsection{Sensitivity Analysis and Industrial Implications}

Regarding the Hypothesis $\mathrm{H}_{1}$, the conclusions and industrial implications are as follows:

- There is a 0.459 probability of having a high level of implementation from Intermediate Systems, because there has is a high level in Stand-Alone Systems, that is, the correct implementation of technology systems, such as CAD, CAPP, CNC, and MWL, which allow a great implementation of systems for AS/RS, AMHS, and AITE.

- The probability of having a high implementation of Intermediate Systems if there is a low implementation of Stand-Alone Systems is 0.000, which indicates that the implementation process of AMT is gradual and it is not possible for a company to have an adequate implementation of the Intermediate Systems if the implementation of Stand-Alone Systems is at a low level, which may be due to the fact that there must be a learning and evolution system in AMT. Therefore, an incorrect or null implementation of Stand-Alone Systems will end in poor material handling systems and inspection, as well as testing in an automated management way. Also, the probability of having a low implementation level in Intermediate Systems if there is a high implementation of Stand-Alone Systems is 0.027 , which indicates that a high level of Stand-Alone Systems is not associated with low implementation levels in Intermediate Systems, confirming the last conclusion.

- Finally, if a company has a low implementation level in Stand-Alone Systems, then it has a risk of 0.446 to have a low level in the Intermediate Systems; therefore, managers must make a huge effort to implement Stand-Alone Systems properly to guarantee successful investment in more expensive technologies.

Similarly, analyzing the sensitivity analysis for Hypothesis $\mathrm{H}_{2}$, the following conclusions can be established:

- If Intermediate Systems have a high implementation level, then there is a probability of 0.534 that Integrated Systems will also have a high level, which means that the correct implementation of AS/RS, AMHS, and AITE systems will guarantee, at a certain level, the appropriate implementation of manufacturing cells, JIT, and that material management may be performed through systems, such as MRP and MRP II.

- The probability of having a high implementation of Integrated Systems if there is a low implementation of Intermediate Systems is 0.018 , which is a risk for managers and they must focus their effort to solve that problem to guarantee benefits. Also, it is almost impossible to have a low implementation on Integrated Systems if there is a high implementation on Intermediate Systems, because the conditional probability is 0.017 . This result allows to conclude again that incremental AMT is required.

- Finally, a low implementation level of Intermediate Systems is highly associated with low implementation on Integrated Systems, because the conditional probability is 0.702 . In other words, as result of low implementation in AS/RS, AMHS, and AITE, then the technologies such as FMC, FMS, CIM, JIT, MRP, and MRP II systems will also have low levels and the managers must focus on guaranteeing an incremental AMT implementation.

For $\mathrm{H}_{3}$, the conclusions and industrial implication confirm how incremental AMT is required due to the following:

- If there are high implementation levels on Stand-Alone Systems, then there is a probability of 0.500 of obtaining Integrated Systems with high levels as well, which indicates that the appropriate 
implementation of technologies systems, such as CAD, CAPP, CNC, and MWL will allow the correct usage of automated material handling technologies such as FMC/FMS, CIM, JIT, MRP, and MRP II.

- The probability of having a high level of implementation on Integrated Systems because the Stand-Alone Systems have not been implemented, is 0.000; it sounds somewhat logical since if a type of isolated AMT has not been implemented before, it is impossible to integrate them into a system and there is a lack of experience in this kind of technologies. Also, the probability for obtaining high implementation on Integrated Systems if Stand-Alone Systems are low, is 0.027, and it means that companies cannot integrate their production systems if they do not have control on their isolated technologies. Therefore, managers must focus on an incremental implementation.

- Finally, in the scenario where the implementation of the Integrated Systems is low if the Stand-Alone Systems are low as well, the probability is 0.482 , which means that if Stand-Alone Systems have not been implemented correctly, as a consequence, the Integrated Systems will not be implemented correctly as well.

The hypotheses $\mathrm{H}_{4}, \mathrm{H}_{5}$, and $\mathrm{H}_{6}$ are the most fundamental, because they measure the relationship between AMT and the Production Benefits obtained. Regarding the $\mathrm{H}_{4}$, the conclusions are as follow:

- There is a probability of 0.338 of obtaining high levels on Production Benefits, such as the reduction of the production cost, time of process, and an increment in product quality, if the Stand-Alone Systems such as CAD, CAPP, CNC, and MWL, as well as robots are implemented correctly.

- Those Stand-Alone Systems with low levels cannot generate Production Benefits in high levels, because the conditional probability is only 0.054 , where managers must pay attention in order to have an adequate technology implementation. Also, to confirm the last conclusion, Stand-Alone Systems in high levels do not generate Production Benefits in low levels, because the conditional probability is 0.027 .

- Finally, the worst situation for a manager is to have a low implementation level in Stand-Alone Systems, because there is a risk of 0.411 of generating a low level in Production Benefits. In other words, managers must focus on obtaining an adequate implementation in CAD, CAPP, NC/CNC, $\mathrm{DNC}$, and MWL, as well as robots, to guarantee low production costs and processing time, a better quality, and capacity.

The conclusions and industrial implications for $\mathrm{H}_{5}$ are as follow:

- There is a probability of 0.345 of obtaining a high level on Production Benefits if Intermediate Systems also have a high level, which indicates that a low production cost and production time are depending on the technology level for AS/RS, AMHS, and AITE. This is relevant, because those technologies are focused on material handling — an important component in a production system that never adds value to the product. This findings are similar to those reported by Danese [75], where AS/RS is highly related with processing time in manufacturing industries.

- However, if Intermediated Systems have a low implementation level, then there is a probability of 0.035 for having Production Benefits, which indicates the importance of guaranteeing an appropriate implementation process. Also, if there are Intermediated Systems at a high level, then Product Benefits will almost never have low levels, because the conditional probability is only 0.052 . In other words, Intermediated Systems in low levels never generate Production Benefits, and that is why managers must focus their efforts on guaranteeing an adequate implementation process.

- Finally, there is a probability or risk of 0.333 of having low levels in Production Benefits if Intermediated Systems have low levels as well. In fact, it means that if technology is used in material handling, then it is difficult to obtain benefits associated with the improvement in layout, better production organization, low set-up time, and space usage.

Finally, regarding the Hypothesis $\mathrm{H}_{6}$ that is related to the Integrated Systems and Production Benefits, the conclusions and industrial implications are as follow: 
- If Integrated Systems have a high implementation level, then there is a conditional probability of 0.491 to have Production Benefits at high levels as well. This means that if FMC/FMS, CIM, JIT, MRP, and MRP II are properly implemented, then companies will acquire low production cost and processing time, better quality, plant capacity, production organization, and reliability. These findings are similar to García-Alcaraz, Macías, Luevano, Fernández, López and Macías [58] that have indicated the relationship between JIT and the benefits acquired, or that associated the SMED with benefits obtained by the maquiladoras.

- However, if Integrated Systems have a low implementation level in production lines, then is almost impossible to obtain high levels in Production Benefits, because the conditional probability is only 0.030; and vice versa, if Integrated Systems have high implementation level, then is almost impossible to obtain low levels in Production Benefits, because the conditional probability is 0.018 . This finding guarantees managers that investing in this type of technology always generates benefits.

- Finally, if Integrated Systems have a low implementation level, then there is a probability of 0.394 of obtaining low levels in Production Benefits, which is mainly due to the high cost of this technology. For example, Wang, Gong and Wang [62] indicated that if MRP has a low implementation, then the cost for material handling is high, while Kenneth W. Green, et al. [76] indicated that a low level in JIT may affect the quality in products and delivery time.

Author Contributions: Conceptualization, J.R.D.-R. and J.L.G.-A.; Data curation, J.R.D.-R. and J.L.G.-A.; Investigation, J.R.D.-R. and J.L.G.-A.; Methodology, J.R.D.-R., J.A.M.-S. and J.L.G.-A.; Validation, J.R.M.-F.; Writing-original draft, J.R.D.-R. and J.L.G.-A.; Writing-review \& editing, J.B.-F. and J.A.M.-S.

Funding: This research received no external funding.

Conflicts of Interest: The authors declare no conflict of interest.

\section{References}

1. Goyal, S.; Grover, S. Advanced manufacturing technology effectiveness: A review of literature and some issues. Front. Mech. Eng. 2012, 7, 256-267. [CrossRef]

2. Ordoobadi, S.M. Application of AHP and Taguchi loss functions in evaluation of advanced manufacturing technologies. Int. J. Adv. Manuf. Technol. 2013, 67, 2593-2605. [CrossRef]

3. Krot, K.; Mazgajczyk, E.; Rusińska, M.; Woźna, A. Strategy of improving skills of innovation managers in the area of advanced manufacturing technologies. In Proceedings of the Intelligent Systems in Production Engineering and Maintenance, Wrocław, Poland, 17-18 September 2019; Springer: Cham, Switzerland, 2019; pp. 296-305.

4. Percival, J.C.; Cozzarin, B.P. Complementarities in the implementation of advanced manufacturing technologies. J. High Technol. Manag. Res. 2010, 21, 122-135. [CrossRef]

5. Small, M.H.; Chen, I.J. Economic and strategic justification of AMT inferences from industrial practices. Int. J. Prod. Econ. 1997, 49, 65-75. [CrossRef]

6. Small, M.H.; Chen, I.J. Investment justification of advanced manufacturing technology: An empirical analysis. J. Eng. Technol. Manag. 1995, 12, 27-55. [CrossRef]

7. Kotha, S.; Swamidass, P.M. Strategy, advanced manufacturing technology and performance: Empirical evidence from US manufacturing firms. J. Oper. Manag. 2000, 18, 257-277. [CrossRef]

8. Sohal, A.S.; Singh, M. Implementing Advanced Manufacturing Technology: Factors Critical to Success. Logist. Inf. Manag. 1992, 5, 39-46. [CrossRef]

9. Beaumont, N.; Schroder, R.; Sohal, A. Do foreign-owned firms manage advanced manufacturing technology better? Int. J. Oper. Prod. Manag. 2002, 22, 759-771. [CrossRef]

10. Aravindan, P.; Punniyamoorthy, M. Justification of Advanced Manufacturing Technologies (AMT). Int. J. Adv. Manuf. Technol. 2002, 19, 151-156. [CrossRef]

11. Meredith, J.; Suresh, N. Justification techniques for advanced manufacturing technologies. Int. J. Prod. Res. 1986, 24, 1043-1057. [CrossRef]

12. Lee, Y.-Q.; Shin, H.-J. CIM implementation through at and MRP integration. Comput. Ind. Eng. 1996, 31, 609-612. [CrossRef] 
13. Kuts, V.; Modoni, G.E.; Terkaj, W.; Tähemaa, T.; Sacco, M.; Otto, T. Exploiting factory telemetry to support virtual reality simulation in robotics cell. In Proceedings of the Augmented Reality, Virtual Reality, and Computer Graphics, Ugento, Italy, 12-15 June 2017; Springer: Cham, Switzerland, 2017; pp. 212-221.

14. Jing, H.; Haihong, E.; Guan, L.; Jian, D. Survey on NoSQL database. In Proceedings of the 6th International Conference on Pervasive Computing and Applications, Port Elizabeth, South Africa, 26-28 October 2011; pp. 363-366.

15. Ghani, K.A.; Jayabalan, V.; Sugumar, M. Impact of advanced manufacturing technology on organizational structure. J. High Technol. Manag. Res. 2002, 13, 157-175. [CrossRef]

16. Ordoobadi, S. Evaluation of advanced manufacturing technologies using Taguchi's loss functions. J. Manuf. Technol. Manag. 2009, 20, 367-384. [CrossRef]

17. Singh, H.; Kumar, R. Measuring the utilization index of advanced manufacturing technologies: A case study. IFAC Proc. Vol. 2013, 46, 899-904. [CrossRef]

18. Garcia-Alcaraz, J.L.; Iniesta, A.; Juárez, M.C. Benefits of advanced manufacturing technologies. Afr. J. Bus. Manag. 2012, 6, 5524-5532. [CrossRef]

19. Kreng, V.B.; Wu, C.-Y.; Wang, I.C. Strategic justification of advanced manufacturing technology using an extended AHP model. Int. J. Adv. Manuf. Technol. 2011, 52, 1103-1113. [CrossRef]

20. Choe, J.-M. Impact of management accounting information and AMT on organizational performance. J. Inf. Technol. 2004, 19, 203-214. [CrossRef]

21. Gothwal, S.; Raj, T. Analyzing the factors affecting the flexibility in FMS using weighted interpretive structural modeling (WISM) approach. Int. J. Syst. Assur. Eng. Manag. 2017, 8, 408-422. [CrossRef]

22. García-Alcaraz, J.L.; Maldonado, A.A.; Iniesta, A.A.; Robles, G.C.; Hernández, G.A. A systematic review/survey for JIT implementation: Mexican maquiladoras as case study. Comput. Ind. 2014, 65, 761-773. [CrossRef]

23. Braglia, M.; Gabbrielli, R. Dimensional analysis for investment selection in industrial robots. Int. J. Prod. Res. 2000, 38, 4843-4848. [CrossRef]

24. Jones, T.C.; Lee, B. Accounting, strategy and AMT investment. Omega 1998, 26, 769-783. [CrossRef]

25. Koc, T.; Bozdag, E. The impact of AMT practices on firm performance in manufacturing SMEs. Robot. Comput. Integr. Manuf. 2009, 25, 303-313. [CrossRef]

26. Chan, F.T.S.; Chan, M.H.; Lau, H.; Ip, R.W.L. Investment appraisal techniques for advanced manufacturing technology (AMT): A literature review. Integr. Manuf. Syst. 2001, 12, 35-47. [CrossRef]

27. INEGI. Monthly Survey of Manufacturing (EMIM). Available online: http://www.inegi.org.mx/sistemas/bie/ default.aspx?idserPadre=10400100 (accessed on 13 June 2016). (In Spanish).

28. García-Alcaraz, J.L.; Martínez-Loya, V.; Díaz-Reza, J.R.; Blanco-Fernández, J.; Jiménez-Macías, E.; López, A.J.G. Effect of ICT integration on SC flexibility, agility and company' performance: The Mexican maquiladora experience. Wirel. Netw. 2019. [CrossRef]

29. Boer, H. Advanced manufacturing technologies and strategically flexible production. A review and outlook. In A Journey through Manufacturing and Supply Chain Strategy Research: A Tribute to Professor Gianluca Spina; Bartezzaghi, E., Cagliano, R., Caniato, F., Ronchi, S., Eds.; Springer International Publishing: Cham, Switzerland, 2016; pp. 71-110.

30. Bülbül, H.; Ömürbek, N.; Paksoy, T.; Bektaş, T. An empirical investigation of advanced manufacturing technology investment patterns: Evidence from a developing country. J. Eng. Technol. Manag. 2013, 30, 136-156. [CrossRef]

31. Cardoso, R.D.R.; Pinheiro de Lima, E.; Gouvea da Costa, S.E. Identifying organizational requirements for the implementation of Advanced Manufacturing Technologies (AMT). J. Manuf. Syst. 2012, 31, 367-378. [CrossRef]

32. Boyer, K.K.; Leong, G.K.; Ward, P.T.; Krajewski, L.J. Unlocking the potential of advanced manufacturing technologies. J. Oper. Manag. 1997, 15, 331-347. [CrossRef]

33. Ghobakhloo, M.; Azar, A. Business excellence via advanced manufacturing technology and lean-agile manufacturing. J. Manuf. Technol. Manag. 2017, 29, 2-24. [CrossRef]

34. Kumar, R.; Singh, H.; Chandel, R. Exploring the key success factors of advanced manufacturing technology implementation in Indian manufacturing industry. J. Manuf. Technol. Manag. 2017, 29, 25-40. [CrossRef] 
35. Altuntas, S.; Cinar, O.; Kaynak, S. Relationships among advanced manufacturing technology, innovation, export, and firm performance: Empirical evidence from Turkish manufacturing companies. Kybernetes 2018, 47, 1836-1856. [CrossRef]

36. Cheng, Y.; Matthiesen, R.; Farooq, S.; Johansen, J.; Hu, H.; Ma, L. The evolution of investment patterns on advanced manufacturing technology (AMT) in manufacturing operations: A longitudinal analysis. Int. J. Prod. Econ. 2018, 203, 239-253. [CrossRef]

37. Sacristán Díaz, M.; Machuca, J.A.D.; Álvarez-Gil, M.A.J. A view of developing patterns of investment in AMT through empirical taxonomies: New evidence. J. Oper. Manag. 2003, 21, 577-606. [CrossRef]

38. Bourke, J.; Roper, S. AMT adoption and innovation: An investigation of dynamic and complementary effects. Technovation 2016, 55-56, 42-55. [CrossRef]

39. Green, K.W.; Inman, R.A.; Birou, L.M.; Whitten, D. Total JIT (T-JIT) and its impact on supply chain competency and organizational performance. Int. J. Prod. Econ. 2014, 147, 125-135. [CrossRef]

40. Ang, J.S.K.; Sum, C.-C.; Chung, W.-F. Critical success factors in implementing MRP and government assistance: A Singapore context. Inf. Manag. 1995, 29, 63-70. [CrossRef]

41. Modoni, G.E.; Sacco, M.; Terkaj, W. A survey of RDF store solutions. In Proceedings of the International Conference on Engineering, Technology and Innovation (ICE), Bergamo, Italy, 23-25 June 2014; pp. 1-7.

42. Gupta, Y.P.; Yakimchuk, M.D. Impact of Advanced Manufacturing Technology on Industrial Relations: A Comparative Study. Int. J. Oper. Prod. Manag. 1989, 9, 5-14. [CrossRef]

43. Dhamija, D.; Koonce, D.A.; Judd, R.P. Development of a unified data meta-model for CAD-CAPP-MRP-NC verification integration. Comput. Ind. Eng. 1997, 33, 19-22. [CrossRef]

44. Campos, J.G.; Miguez, L.R. Standard process monitoring and traceability programming in collaborative CAD/CAM/CNC manufacturing scenarios. Comput. Ind. 2011, 62, 311-322. [CrossRef]

45. Fulton, M.; Hon, B. Managing advanced manufacturing technology (AMT) implementation in manufacturing SMEs. Int. J. Product. Perform. Manag. 2010, 59, 351-371. [CrossRef]

46. Zhou, X.; Qiu, Y.; Hua, G.; Wang, H.; Ruan, X. A feasible approach to the integration of CAD and CAPP. Comput. Aided Des. 2007, 39, 324-338. [CrossRef]

47. Milosevic, M.; Lukic, D.; Antic, A.; Lalic, B.; Ficko, M.; Simunovic, G. e-CAPP: A distributed collaborative system for internet-based process planning. J. Manuf. Syst. 2017, 42, 210-223. [CrossRef]

48. Brecher, C.; Wellmann, F.; Epple, A. Quality-predictive CAM Simulation for NC Milling. Procedia Manuf. 2017, 11, 1519-1527. [CrossRef]

49. Brecher, C.; Lohse, W. Evaluation of toolpath quality: User-assisted CAM for complex milling processes. CIRP J. Manuf. Sci. Technol. 2013, 6, 233-245. [CrossRef]

50. Utstumo, T.; Urdal, F.; Brevik, A.; Dørum, J.; Netland, J.; Overskeid, Ø.; Berge, T.W.; Gravdahl, J.T. Robotic in-row weed control in vegetables. Comput. Electron. Agric. 2018, 154, 36-45. [CrossRef]

51. Zhang, Q.; Vonderembse, M.A.; Cao, M. Achieving flexible manufacturing competence: The roles of advanced manufacturing technology and operations improvement practices. Int. J. Oper. Prod. Manag. 2006, 26, 580-599. [CrossRef]

52. Lin, J.T.; Wu, C.-H.; Huang, C.-W. Dynamic vehicle allocation control for automated material handling system in semiconductor manufacturing. Comput. Oper. Res. 2013, 40, 2329-2339. [CrossRef]

53. Glüer, D.; Sturm, R. Integration of Real Factory Variability in AMHS Simulations for Wafer Fabs. IFAC Proc. Vol. 2006, 39, 679-684. [CrossRef]

54. Lemos, M.A.; Liberado, E.V.; Marques, M.A.; Junior, G.B. Towards Intelligent Manufacturing. IFAC Proc. Vol. 2007, 40, 73-78. [CrossRef]

55. Baena, F.; Guarin, A.; Mora, J.; Sauza, J.; Retat, S. Learning Factory: The Path to Industry 4.0. Procedia Manuf. 2017, 9, 73-80. [CrossRef]

56. Fullerton, R.R.; McWatters, C.S. The production performance benefits from JIT implementation. J. Oper. Manag. 2001, 19, 81-96. [CrossRef]

57. Maiga, A.S.; Jacobs, F.A. JIT performance effects: A research note. Adv. Account. 2009, 25, 183-189. [CrossRef]

58. García-Alcaraz, J.L.; Macías, A.A.M.; Luevano, D.J.P.; Fernández, J.B.; López, A.D.J.G.; Macías, E.J. Main benefits obtained from a successful JIT implementation. Int. J. Adv. Manuf. Technol. 2016, 86, 2711-2722. [CrossRef]

59. Singh, S.; Garg, D. JIT System: Concepts, Benefits and Motivation in Indian Industries. Int. J. Manag. Bus. Stud. 2011, 1, 26-30. 
60. Schroeder, R.G.; Anderson, J.C.; Tupy, S.E.; White, E.M. A study of MRP benefits and costs. J. Oper. Manag. 1981, 2, 1-9. [CrossRef]

61. Sum, C.-C.; Yang, K.-K.; Ang, J.S.K.; Quek, S.-A. An analysis of Material Requirements Planning (MRP) benefits using Alternating Conditional Expectation (ACE). J. Oper. Manag. 1995, 13, 35-58. [CrossRef]

62. Wang, H.; Gong, Q.; Wang, S. Information processing structures and decision making delays in MRP and JIT. Int. J. Prod. Econ. 2017, 188, 41-49. [CrossRef]

63. Vonglao, P. Application of fuzzy logic to improve the Likert scale to measure latent variables. Kasetsart J. Soc. Sci. 2017, 38, 337-344. [CrossRef]

64. Galván, O.; García, J. Analysis of the Historical Development of the Maquiladora Export Industry in Mexico. Rev. Doxa 2018, 8, 135-152. (In Spanish)

65. Kline, R.B. Principles and Practice of Structural Equation Modeling; Guilford Publications: New York, NY, USA, 2015.

66. Ajayi, S.O.; Oyedele, L.O. Critical design factors for minimising waste in construction projects: A structural equation modelling approach. Resour. Conserv. Recycl. 2018, 137, 302-313. [CrossRef]

67. Kock, N. Using WarpPLS in e-collaboration studies: Mediating effects, control and second order variables, and algorithm choices. Int. J. E Collab. 2011, 7, 1-13. [CrossRef]

68. Hair, J.F.; Ringle, C.M.; Sarstedt, M. Editorial-partial least squares structural equation modeling: Rigorous applications, better results and higher acceptance. Long Range Plan. 2013, 46, 1-12. [CrossRef]

69. Kock, N. Advanced mediating effects tests, multi-group analyses, and measurement model assessments in PLS-based SEM. Int. J. E Collab. 2014, 10, 1-13. [CrossRef]

70. Moqbel, M.; Kock, N.; Nevo, S. Organizational members' use of social networking sites and job performance: An exploratory study. Inf. Technol. People 2013, 26, 240-264. [CrossRef]

71. Kock, N. WarpPLS User Manual: Version 6.0; ScriptWarp Systems: Laredo, TX, USA, 2017.

72. Ross, S.M. 3-Conditional probability and conditional expectation. In Introduction to Probability Models, 12th ed.; Ross, S.M., Ed.; Academic Press: Cambridge, MA, USA, 2019; pp. 101-191.

73. Alimohammadlou, M.; Eslamloo, F. Relationship between Total Quality Management, Knowledge Transfer and Knowledge Diffusion in the Academic Settings. Procedia Soc. Behav. Sci. 2016, 230, 104-111. [CrossRef]

74. Miclo, R.; Fontanili, F.; Lauras, M.; Lamothe, J.; Milian, B. An empirical comparison of MRPII and Demand-Driven MRP. IFAC Pap. 2016, 49, 1725-1730. [CrossRef]

75. Danese, P. JIT production, JIT supply and performance: Investigating the moderating effects. Ind. Manag. Data Syst. 2012, 112, 441-465. [CrossRef]

76. Green, K.W.; Inman, R.A.; Sower, V.E.; Zelbst, P.J. Impact of JIT, TQM and green supply chain practices on environmental sustainability. J. Manuf. Technol. Manag. 2019. [CrossRef] 